\title{
EFFECTIVENESS OF HOT ISOSTATIC PRESSING ON HEALING OXIDE FILM DEFECTS IN CAST ALUMINIUM ALLOYS
}

\author{
C. Nyahumwa \\ Department of Engineering Materials, University of Dar es Salaam, \\ P.O. Box 35131, Dar es Salaam, Tanzania
}

\begin{abstract}
$\mathbf{H}$ ot isostatic pressing (hipping) of cast aluminium alloys is recognized as a means of providing improved internal soundness and mechanical properties of the castings. However, little is known about the limitations and potential benefit of the hipping process to produce reliable aluminium alloy castings containing oxide film defects due to turbulently filling of moulds. In this study, oxide film defects and fatigue lives of turbulent filled unfiltered Al-7Si-Mg alloy castings have been characterised in as-cast and hipped conditions to quantify the effectiveness of hot isostatic pressing on healing oxide film defects in the castings. The average fatigue life and fatigue life at 0.1 percent failure rate of Al-7Si-Mg alloy castings improve substantially following hipping treatment that also reduces significantly the scatter of the fatigue life data of the castings. This indicates that solid state hipping is a robust process to de-activate oxide film defects in Al-7Si-Mg alloy castings in which transformation of oxide film structure does promote the diffusion bonding across oxide film interfaces. This, however, contrasts with the behaviour of oxide inclusions in Al$10 \mathrm{Mg}$ alloy castings in which magnesium oxide film, whose structure is stable and does not transform during hipping, is possibly resistant to form effective bonding across the oxide film interfaces.
\end{abstract}

Keywords: Oxide film defects; Hot isostatic pressing; Aluminium alloys; Diffusion bonding.

\section{INTRODUCTION}

The application of hot isostatic pressing (hipping) treatment to heal casting defects such as micro-porosity resulting from both gas and shrinkage is now accepted as an effective means of improving the mechanical properties and reliability of aluminium alloy castings [111]. In this process a casting component is subjected to both elevated temperature and isostatic gas pressure in an autoclave for a specified duration. The most widely used pressuring gas is argon [6].

Hipping process parameters for a cast alloy, which comprise temperature, pressure, and time, are selected such that they are sufficient to achieve closure of internal voids and microporosity in the casting through a combination of plastic deformation, creep, and diffusion [6]. The temperature used in the hipping process of Al-7Si-Mg alloy castings is generally ranging from 535 to $545^{\circ} \mathrm{C}$ without causing incipient melting [8]. The ideal pressure is typically as low as possible but must be greater than yield strength of the alloy at temperature used [8]. The duration of hipping treatment is also important and typically ranges from 3 to 5 hours for aerospace grade cast aluminium alloys $[8,9,11]$ although due to the high cost of the process the cycle time used is sufficient to produce radiographically sound casting. Several studies $[3,5,6]$ recommend hipping process parameters for Al-7Si-Mg alloy (A356) castings to be pressure of $103 \mathrm{MPa}$, temperature of $510^{\circ} \mathrm{C}$, and holding time in the range between 2 and 6 hours.

Wakefield and Sharp $[9,11]$ reported that any benefit of the hot isostatic pressing (hipping) process was overridden by the presence of oxide inclusions in the material when they studied the effect of hot isostatic pressing on the fatigue properties of cast $\mathrm{Al}-10 \mathrm{Mg}$ alloy (AA520). Hipping treatment (50 MPa at $420^{\circ} \mathrm{C}$ for $5 \mathrm{hrs}$ ) was found to increase greatly the scatter in fatigue life. This was because the fatigue properties of hipped specimens, which were free of oxide inclusions, improved dramatically due to 'healing' of the shrinkage pores, whereas the properties of those specimens that contained oxide inclusions in significant quantities were not improved.

The purpose of this study was to investigate the effectiveness of hot isostatic pressing to 
heal oxide film defects in cast aluminium alloys. The effectiveness of hot isostatic pressing was quantified on the basis of average fatigue life, fatigue life at 0.1 percent failure rate, and standard deviation of fatigue life data for Al-7Si-Mg alloy castings and compared with those reported for cast $\mathrm{Al}-10 \mathrm{Mg}$ alloy castings $[9,11]$.

\section{A STATISTICAL METHOD FATIGUE DATA ANALYSIS}

There have been a number of attempts to describe the distribution of scattered data as typically found from attempts to measure the strengths or to obtain fatigue data of materials. The Normal (Gaussian) distribution model is sometimes applied to describe most of the data of measured processes [12,13]. For example, in evaluating the failure rate of specimens failed from one type of defect under fatigue condition, the cumulative failure probability $F_{\mathrm{N}}(N)$ of each specimen is expressed as:

$$
F_{N}(N)=\frac{1}{s \sqrt{2 \pi}} \int_{-\infty}^{N} \exp \left[-\frac{1}{2}\left(\frac{N-\mu}{s}\right)^{2}\right] d N
$$

where, $F_{\mathrm{N}}(N)$ is a statistical fraction of castings that failed at given cycles (time) $N$, or lower; $\mu$ is a position parameter for specimens failed from a single defect distribution; and $s$ is a width parameter (standard deviation) for specimens failed from a single defect distribution. The low value of standard deviation indicates a high degree of homogeneity (less scatter of fatigue life data). For normal distribution the failure probability, $F_{\mathrm{N}}(N)$, of a specimen in a sample is converted to that of a population of the same specimens using the relation [12]:

$$
F_{N}(N)=\left(\frac{j-0.3}{n_{t}+0.4}\right)
$$

where, $j$ is the ranked position of the specimen fatigue life in that set of castings, and $n_{\mathrm{t}}$ is the total number of specimens.

For a set of life data in which the scatter is purely the result of random experimental errors, a normal probability plot of $F_{\mathrm{N}}(N)$ versus fatigue life, $N$, would produce a straight line plot. A lognormal distribution model is normally used to describe fatigue life data from fatigue-tested components [12, 13]. Standard normal variate, $Z$, is determined for each cumulative failure probability, $F_{\mathrm{N}}(N)$, which is evaluated using the failure estimator given in equation (2). This is determined after the fatigue life data being ranked for each sample size. The variates, $Z$, then are plotted against the $\ln (N)$ values. The average logarithm of fatigue lives $(\ln N)_{\text {ave }}$ is a value corresponding to $Z=0$ on the straight line plot. Similarly, the standard deviation $S_{\ln }$, which is for natural logarithm values of fatigue life data, is the reciprocal of a slope value of the straight-line plot. The $(\ln N)_{\text {ave }}-3 S_{\text {ln }}$ value, which is a natural logarithm value of fatigue life below which 0.1 percent of components failed, is usually denoted by $-3 S_{\ln }$.

\section{EXPERIMENTAL DETAILS}

\subsection{Casting methods}

The material used in this study was an Al-7SiMg alloy (A356 ASTM B26, BS 2L99). To ensure the inherent of oxide film defects in the castings, a turbulent filling system without filtration as shown in Figure 1a was used to produce cast test bars. Figure $1 \mathrm{~b}$ presents a line drawing from the $x$-ray video of mould filling indicating how liquid metal suffered turbulence in the empty filter print at the bottom of the sprue before it entered into side runners. Round test specimens of $12 \mathrm{~mm}$ diameter of Al-7Si-Mg alloy (2L99) were cast in moulds made of resin-bonded silica sand. The casting temperature was in the range from 725 to $730^{\circ} \mathrm{C}$. 


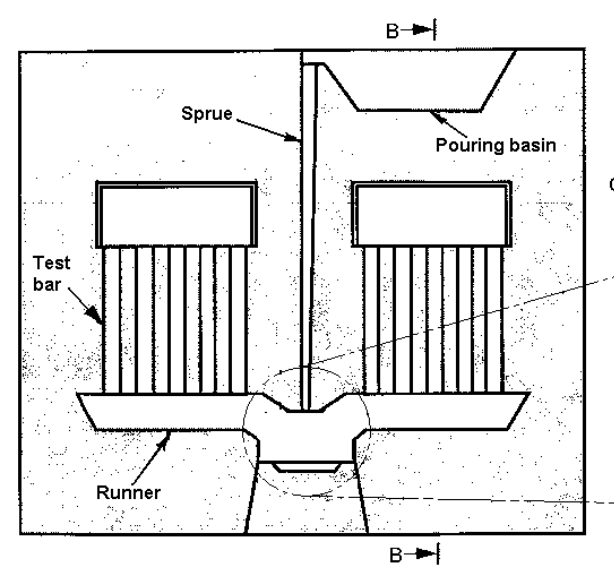

SECTONA-A

(a)

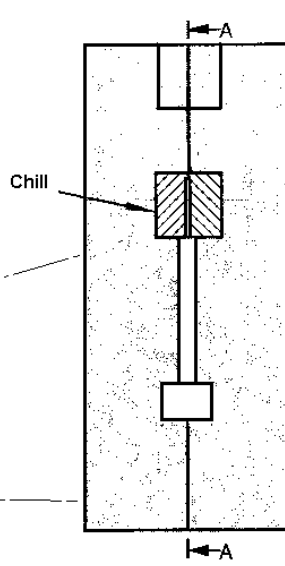

SECTION B-B

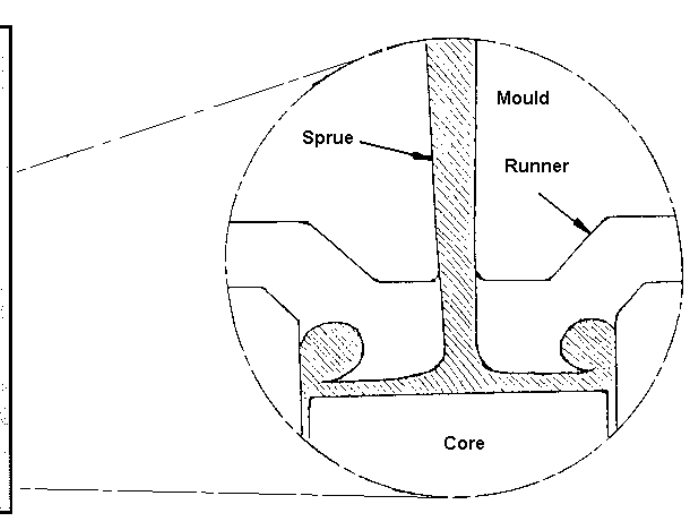

(b)

Figure 1 (a) A mould filling system used to produce turbulent filled unfiltered Al-7Si-Mg alloy castings; (b) A line drawing from a frame of the x-ray video of filling showing the brief surface turbulence.

\subsection{Hot isostatic pressing and heat treatment}

Some turbulent filled unfiltered castings were hipped using a VG Super-hipper. The hipping treatment in this study was performed at a pressure of $100 \mathrm{MPa}$, a temperature of $500^{\circ} \mathrm{C}$, and holding time of $6 \mathrm{hrs}$. The hipping process was carried out before the castings were solution heat-treated and the castings were not canned. The as-cast test bars and those that had been hipped were subjected to identical T6 heat treatment. This involved solution heat treatment for 6 hours at $540^{\circ} \mathrm{C}$, water quenched at room temperature, and artificially aged for 5 hours at $160^{\circ} \mathrm{C}$.

\subsection{Metallography}

As-cast and hipped test bars were examined by optical and scanning electron microscope (SEM) to determine the soundness or integrity of the cast bars. The examination involved the study of defects such as micro-porosity resulting from both gas and shrinkage, and oxide films.

\subsection{Fatigue testing}

Fatigue tests were performed on unfiltered non-hipped and unfiltered hipped specimens whose dimensions are shown in Figure 2. The tests involved high cycle fatigue (HCF) that was performed at a maximum stress of 150 $\mathrm{MPa}$ using an Amsler Vibrophore machine, and low cycle fatigue (LCF) that was carried out at a maximum stress of $240 \mathrm{MPa}$ using a DARTEC servo-hydraulic machine. The specimens were cycled in alternating tensiontension with stress ratio $\mathrm{R}=+0.1$.

\subsection{Fractography}

The micro-fractographic examination was carried out on the fracture surface of all fatigue-tested specimens using JEOL 6300 and JEOL 5200 scanning electron microscopes (SEM). The fatigue crack initiator was identified in every specimen. Qualitative x-ray microanalysis using an ultra-thin window (UTW) on the JEOL 6300 SEM and QX 2000 system complimented the fractographic examination by providing energy dispersive $x$ ray (EDX) spectra for the study of chemical composition of oxide film defects that acted as fatigue crack initiators. 


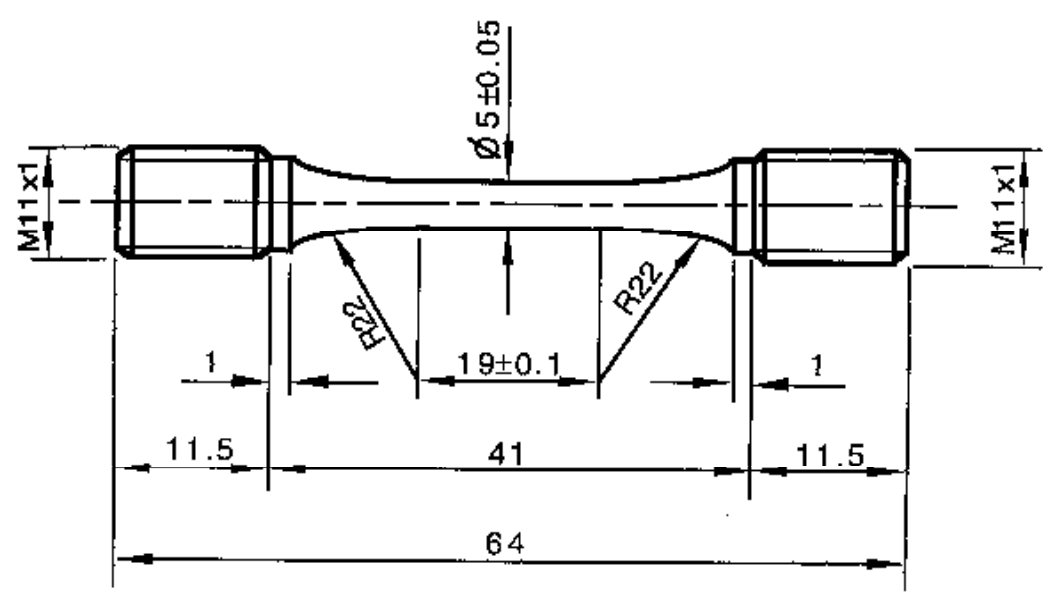

Dimensions: $\mathrm{mm}$

Figure 2 Fatigue specimen geometry

\subsection{Lognormal statistical analysis}

The lognormal distribution model for a single defect distribution was applied to describe fatigue life data of the unfiltered non-hipped and unfiltered hipped Al-7Si-Mg alloy castings. This was to quantify the effectiveness of hot isostatic pressing on healing oxide film defects and pores associated with oxide film defects that acted as fatigue crack initiators. The statistical analysis was performed using general curve fit function in Kaleidagraph software.

\section{RESULTS AND DISCUSSION}

\subsection{Metallographic morphology and crack size of oxide defects}

Almost all specimens cast by the turbulent filled unfiltered running system, which were not subjected to hipping treatment, were observed to contain simple (linear) and complex (tangled) networks of oxide films which revealed big cracks and pores. The oxide films were randomly distributed within the cast test bars. Figure 3 shows an optical micrograph of such oxide films, showing their crack-like nature. Frequently, pores were observed to be attached to the oxide films; this is most likely to be air entrained during folding of the liquid metal surface under conditions of turbulent flow (Figure 4).

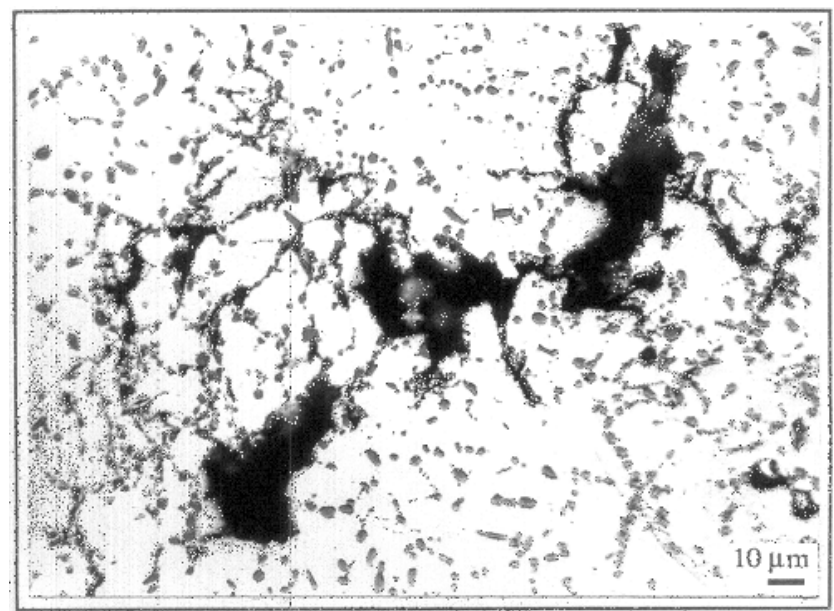

Figure 3 Optical micrograph showing a tangled network of oxide film and attached micropores in an unfiltered non-hipped Al-7Si-Mg casting. 


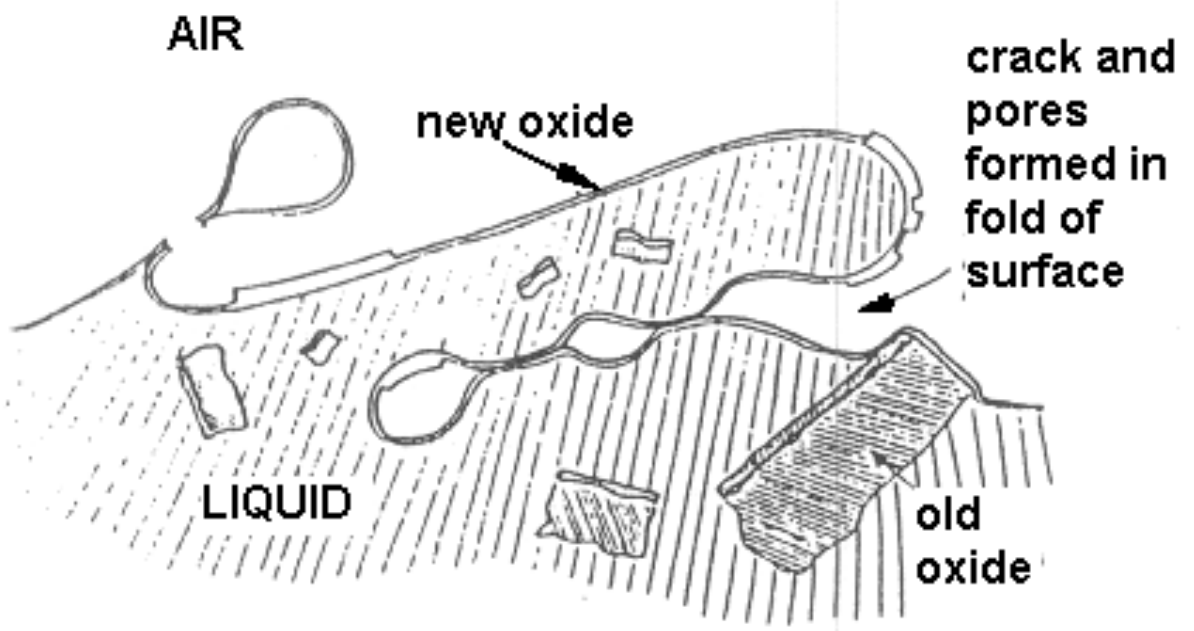

Figure 4 Surface entrainment leading to the formation of oxide film defects and pores.

Test bars which were cast using turbulent filled unfiltered running system and then hipped were also observed to contain networks of oxide films. However, the morphology of these oxide film networks, their crack-like nature in particular, and pores associated with them (Figure 5) differ completely from those observed in turbulent filled unfiltered and nonhipped castings (Figure 3). The cracks and pores in the networks of oxide films were partially or fully closed. When the oxide film network was closely observed on SEM at a higher magnification, some material was observed between two surfaces of oxide films (crack-like) and within a collapsed pore (Figure 6a). Results of energy dispersive x-ray (EDX) microanalysis carried out on one of these sites (Figure 6a) are shown in Figure 6b. As can be seen on the energy spectrum, the oxygen peak is significantly high showing that the material enclosed is oxide.

Oxide film defects in unfiltered non-hipped castings constituted cracks showing no bond developed across the oxide-oxide interface (Figure 3). Widths between the two dry surfaces of folded oxide film were found to vary between 1 and $10 \mu \mathrm{m}$. Widths of cracks associated with pores were significantly greater than $10 \mu \mathrm{m}$. Unlike the crack-like nature of oxides in the unfiltered non-hipped, crack widths of oxide film defects in unfiltered hipped castings were less than $1 \mu \mathrm{m}$ (Figure 5). This was evidence that closure of oxide film defects occurred during hipping treatment (100 $\mathrm{MPa}$ at $500^{\circ} \mathrm{C}$ for $6 \mathrm{hrs}$ ).

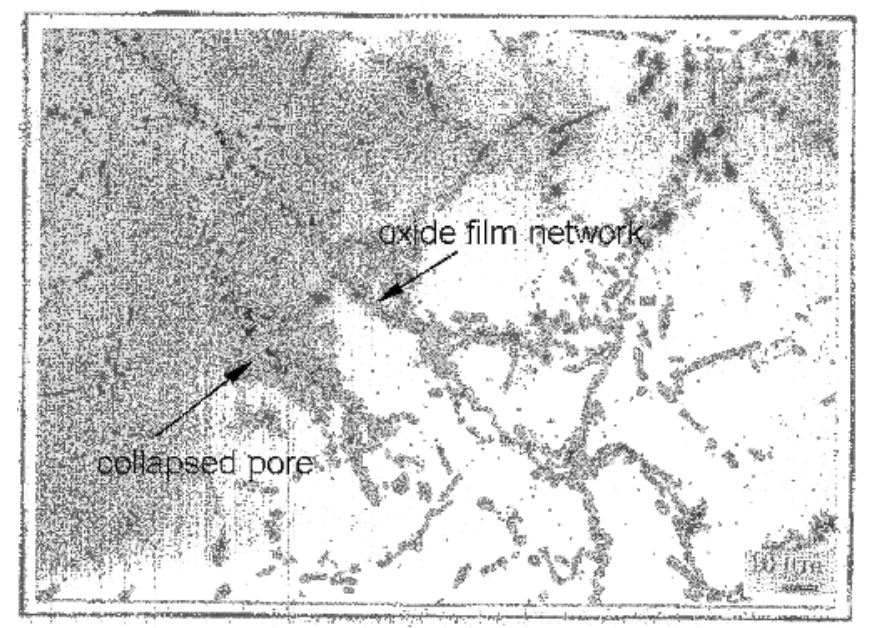

Figure 5 Optical micrograph showing a tangled network of oxide film and attached micropores in an unfiltered hipped Al-7Si-Mg casting. 


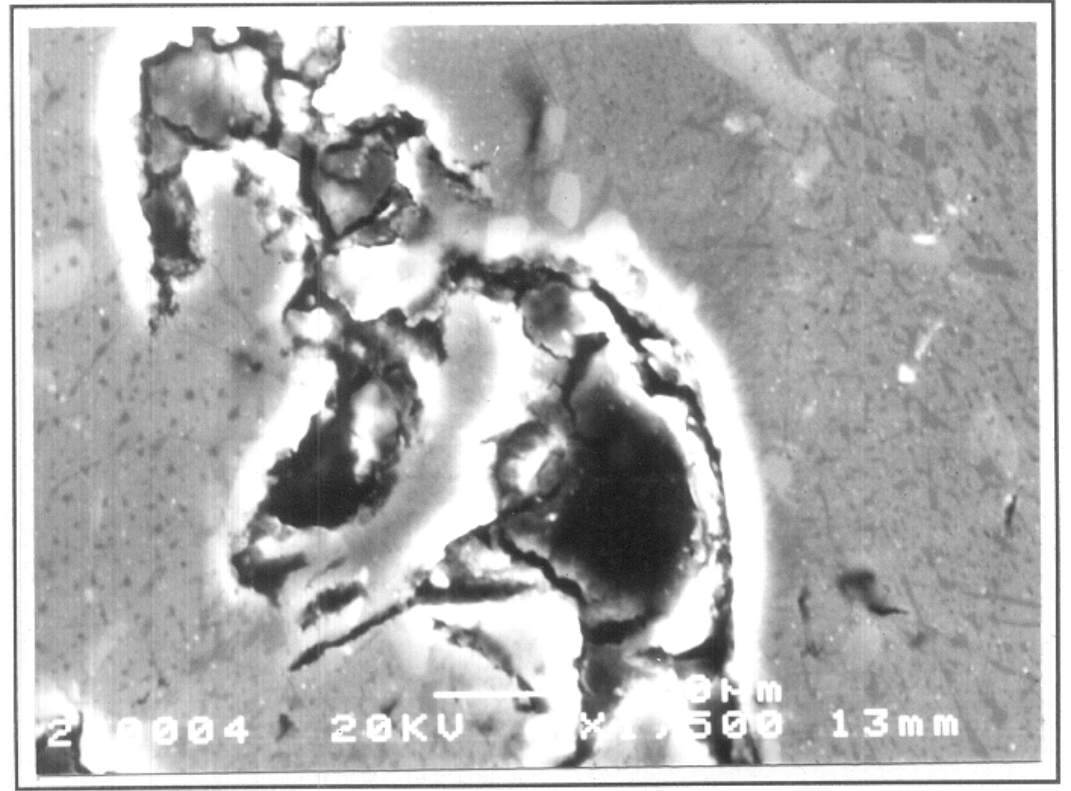

(a)

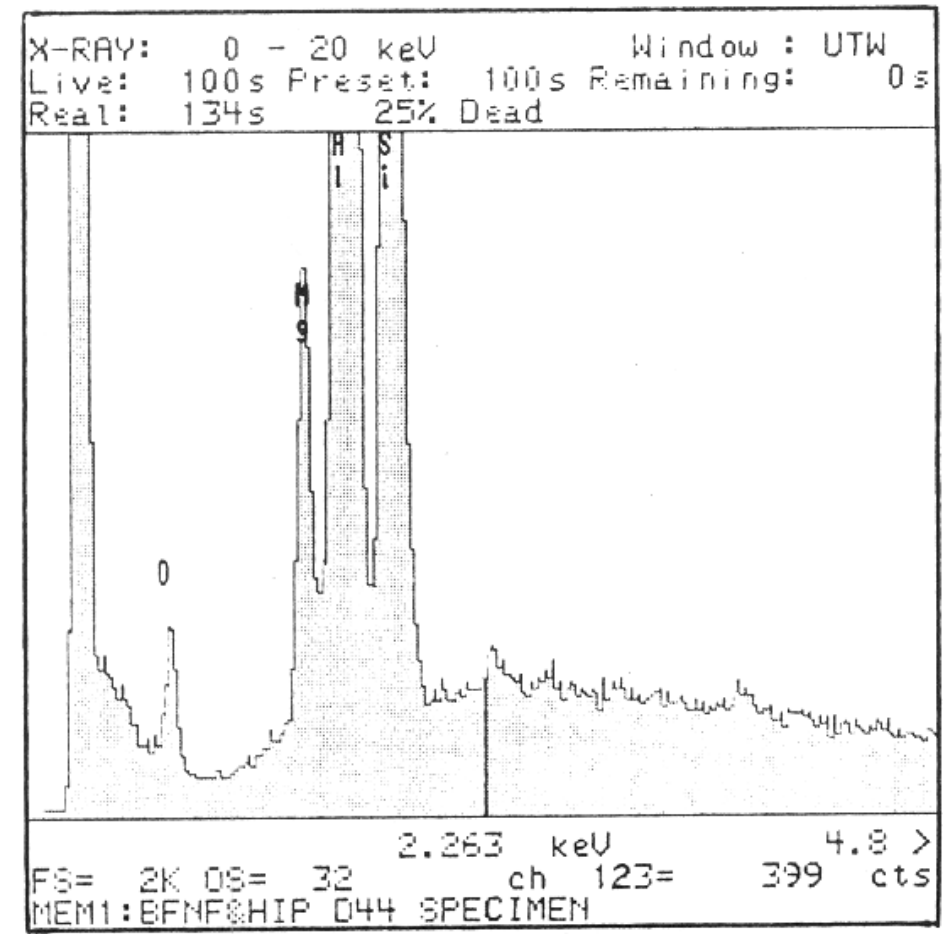

(b)

Figure 6 (a) Secondary electron micrograph showing a collapsed pore attached to a network of oxide film in an unfiltered hipped Al-7Si-Mg alloy casting; (b) Energy dispersive x-ray microanalysis from a site as presented in (a).

\subsection{Fatigue behaviour of as-cast and hipped aluminium alloy castings}

A simple probability plot of the fatigue life distributions of the $150 \mathrm{MPa}$ castings is shown in Figure 7. The fatigue lives of the unfiltered non-hipped castings range from $4 \times 10^{4}$ to $7.4 \times$
$10^{6}$ cycles, whilst those of the unfiltered hipped castings are in the range of $1.7 \times 10^{7}$ and $7.6 \times$ $10^{7}$ cycles. This range of fatigue lives, however, is for the specimens suspended from the experiments (run-outs), and is used to characterise the fatigue strength of cast aluminium alloys [14]. In the range from $5.9 \times$ 
$10^{6}$ to $7.4 \times 10^{6}$ cycles, only three out of thirty two unfiltered non-hipped castings were observed to have failed by slip mechanism. This supports the run-out results of the hipped castings in which the maximum defect size in these castings may have been close to or less than the critical defect sizes for the alloy at this stress level.
Figure 8 presents a simple probability plot of the fatigue lives of the $240 \mathrm{MPa}$ castings. The fatigue lives of the unfiltered non-hipped castings range from $5.1 \times 10^{3}$ to $9.8 \times 10^{4}$ cycles, whilst those of the unfiltered hipped castings are in the range of $2 \times 10^{4}$ and $4.4 \times 10^{5}$ cycles.

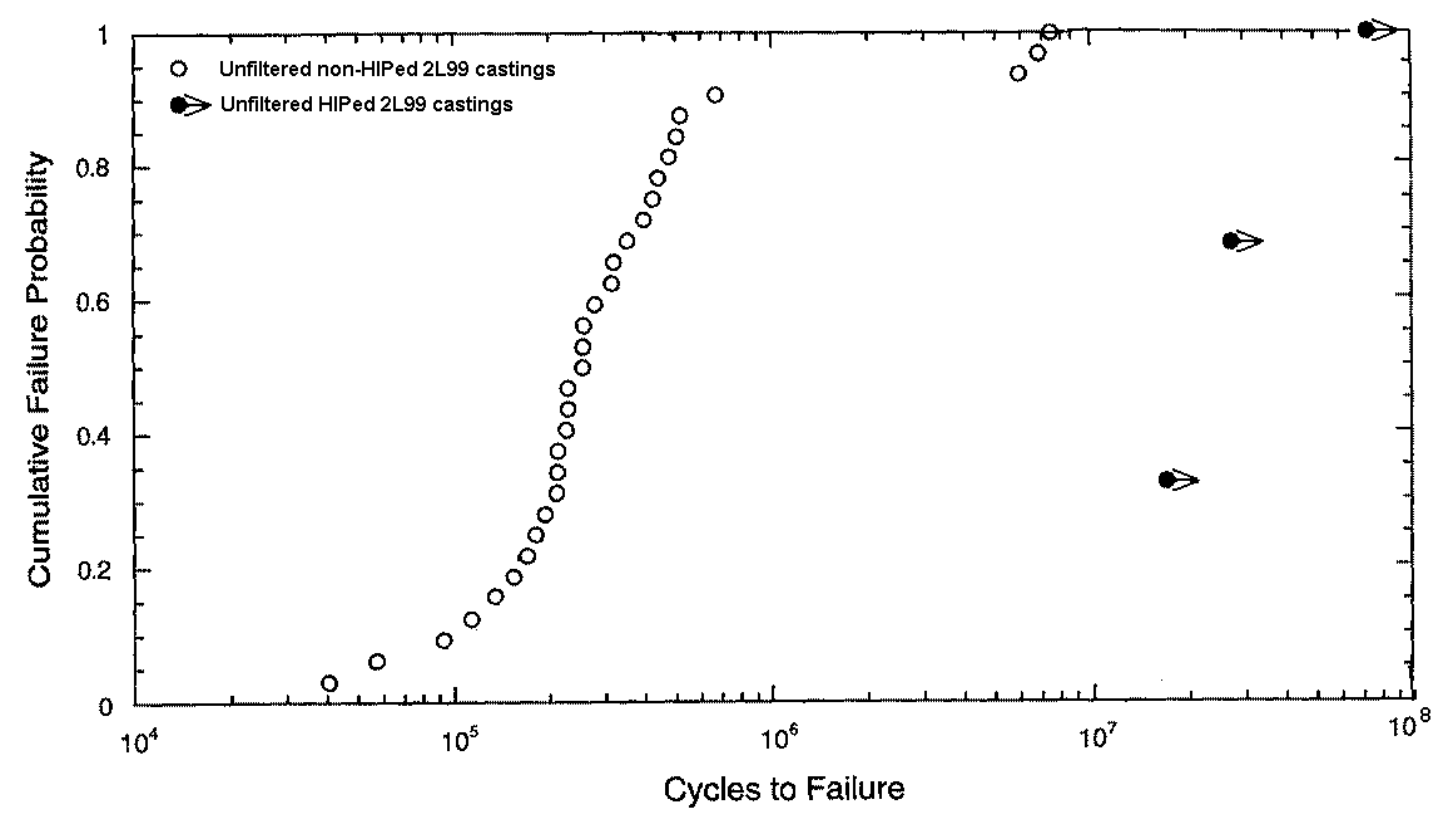

Figure 7 Fatigue life distributions for $150 \mathrm{MPa}$ unfiltered non-hipped and unfiltered hipped Al7Si-Mg alloy castings.

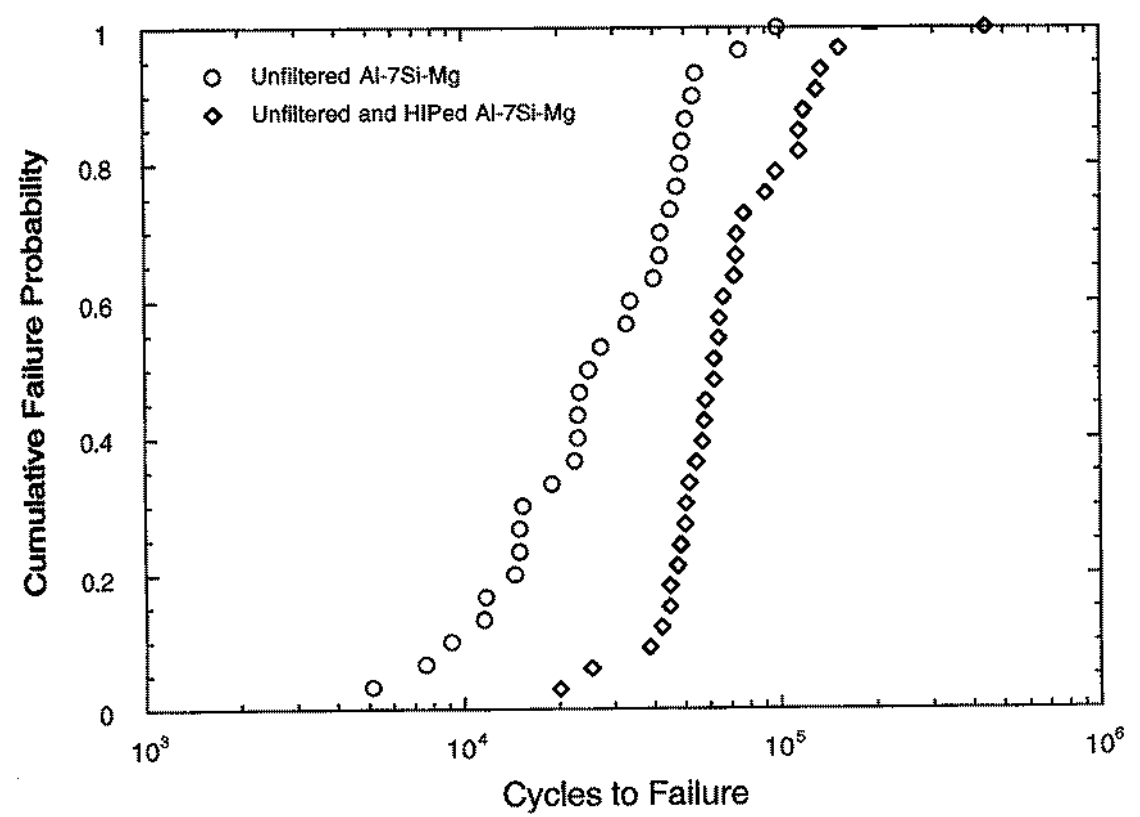

Figure 8 Fatigue life distributions for $240 \mathrm{MPa}$ unfiltered non-hipped and unfiltered hipped Al7Si-Mg alloy castings. 
The fatigue lives of the unfiltered hipped Al7Si-Mg alloy castings were higher than those of unfiltered non-hipped at both applied stresses 150 and $240 \mathrm{MPa}$. At $150 \mathrm{MPa}$ the fatigue lives of the unfiltered hipped castings were 80 times greater than those of the unfiltered non-hipped castings (Figure 7). At $240 \mathrm{MPa}$ the fatigue lives of the unfiltered hipped castings were 1.3 to 4.5 times greater than those of the unfiltered nonhipped castings at any probability of failure (Figure 8). This suggests that the oxide film defects in the unfiltered hipped castings were substantially de-activated by hipping [15], thereby enhancing the fatigue lives of the castings.

In order to understand the response of oxide films and their associated defects during hipping treatment of cast aluminium alloys, the fatigue life data of the $150 \mathrm{MPa}$ Al-7Si-Mg alloy castings were compared to those previously reported for $\mathrm{Al}-10 \mathrm{Mg}$ castings by Wakefield and Sharp $[9,11]$. Their results, together with those obtained in this study have been plotted and shown in Figure 9. Oxide inclusions and porosity were reported to control the fatigue life of non-hipped Al-10Mg alloy castings. A similar effect was observed on the fatigue life of the unfiltered non-hipped Al-7Si-Mg alloy (2L99) castings whose fatigue crack initiators were oxide films, and pores attached to the oxide films. Nevertheless, the fatigue lives of unfiltered hipped Al-7Si-Mg alloy castings are higher than those of hipped Al-10Mg alloy castings (Figure 9).

Wakefield and Sharp [9, 11] attributed the improvement in fatigue life of the best ten castings to contain only micro-pores and no oxide defects (Figure 10). The pores were assumed to have healed by hipping and the material therefore free of casting defects, necessitating fatigue crack initiation by slip mechanism. In their remaining nine hipped castings, oxide film defects were observed to initiate fatigue cracks. They concluded that hipping gave no improvement in the fatigue life of specimens containing oxides, and further reported that oxide films in hipped $\mathrm{Al}-10 \mathrm{Mg}$ alloy castings proved impossible to de-activate and the films therefore overrode the effect of hipping on the fatigue properties of the castings. The magnesium film whose structure does not transform during hipping would, therefore, be resistant to forming bonds. However, a comparison between the fatigue lives of non-hipped and hipped Al-10Mg specimens indicates that there was some improvement in fatigue life in oxide containing specimens (Figure 10). This suggests that the oxide defects might have partially healed by diffusion.

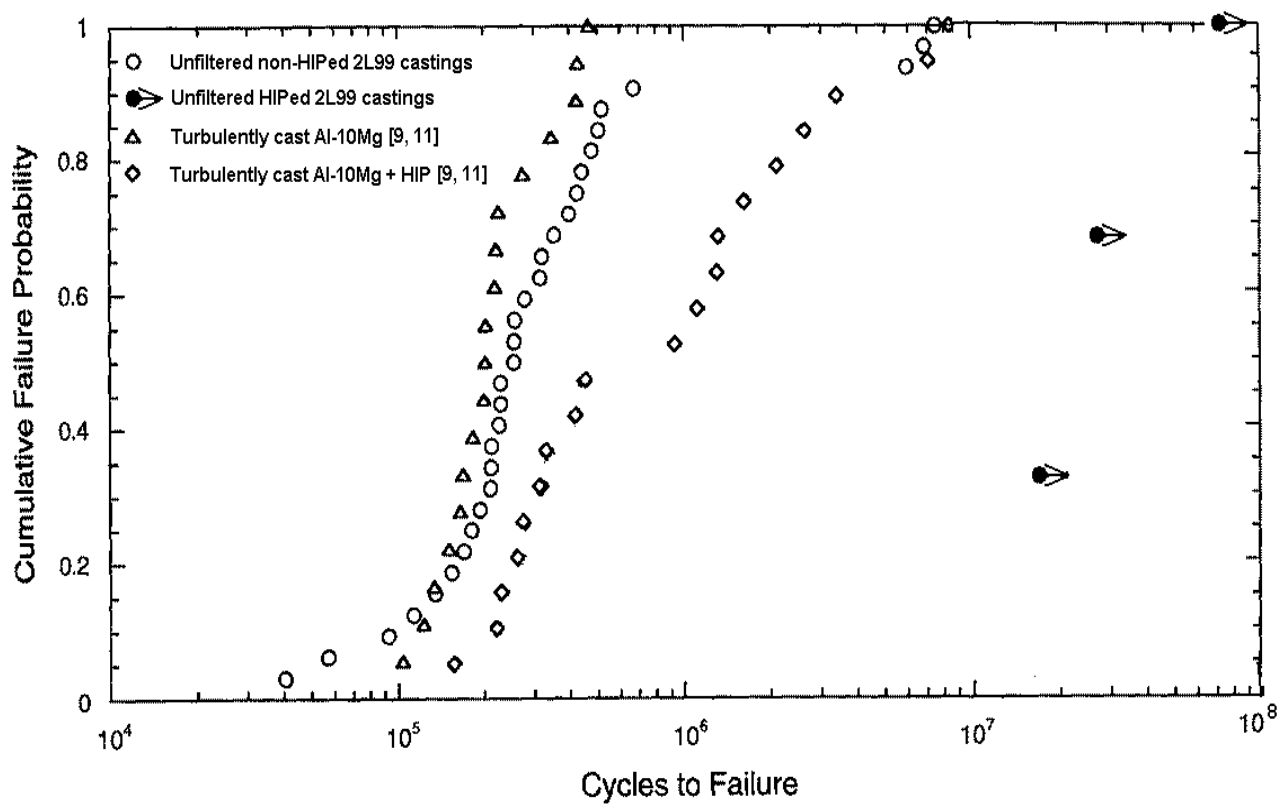

Figure 9 A comparison of fatigue life distributions for $150 \mathrm{MPa}$ Al-7Si-Mg (2L99) alloy castings in the present work and those for $106 \mathrm{MPa} \mathrm{Al}-10 \mathrm{Mg}$ alloy castings in previous study [9, $11]$. 


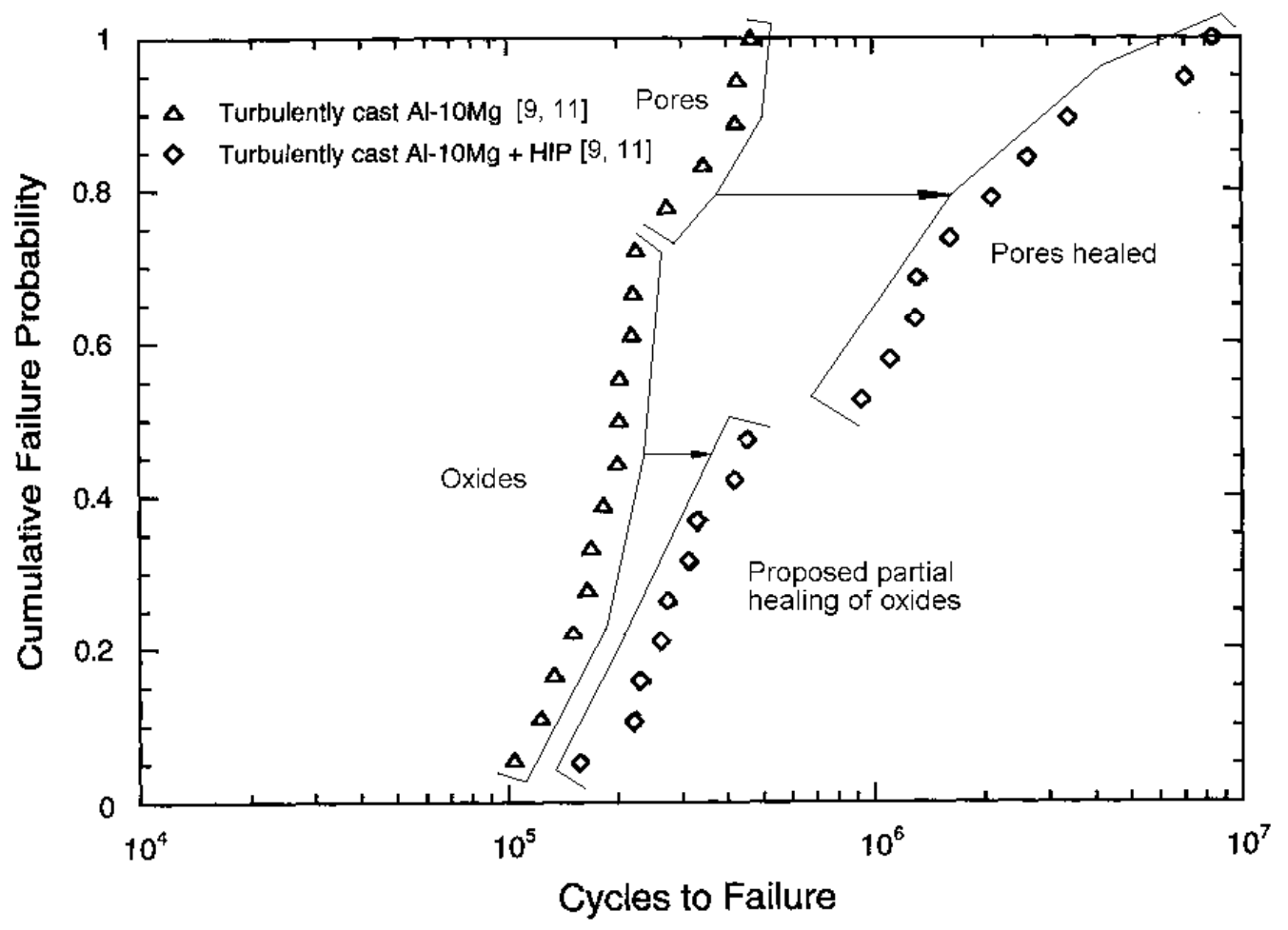

Figure 10 Illustration of improvement of fatigue lives of $106 \mathrm{MPa} \mathrm{Al}-10 \mathrm{Mg}$ alloy castings after hipping $[9,11]$.

\subsection{Fractographic morphology of oxide defects}

Oxide film defects that initiated fatigue failures in unfiltered non-hipped castings have features shown in Figure 11a, and their results of energy dispersive $\mathrm{x}$-ray (EDX) analysis indicated high concentration of oxygen (Figure 11b). These features are different from those of oxide films shown in Figure 12a that acted as fatigue crack initiators in unfiltered hipped castings. The oxide films exhibited voids that may have contributed to healing of the oxide film defects by allowing soft solid material in the Al-7Si-Mg alloy casting to exude easily and bond [16-19]. Energy dispersive x-ray analysis result corresponding to the oxide defect is shown in (Figure 12b). A proportion of $\mathrm{MgAl}_{2} \mathrm{O}_{3}$ spinel and $\mathrm{Al}_{2} \mathrm{O}_{3}$ crystals whose transformation from amorphous $\mathrm{Al}_{2} \mathrm{O}_{3}$ may have also promoted the diffusion bonding across oxide interfaces which were brought together by macroscopic deforming forces (Figure 5). The concept of oxide film being healed in the castings during hipping is developed in Reference [15] and is termed as a solid-state oxide film healing mechanism. 


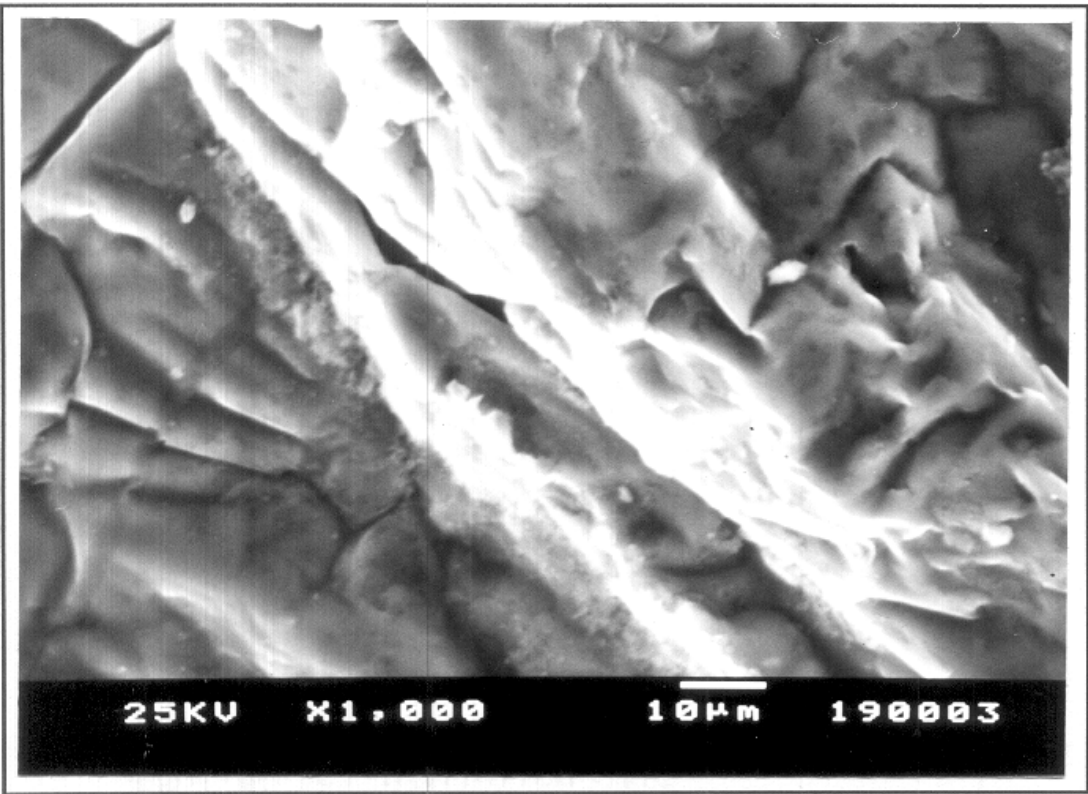

(a)

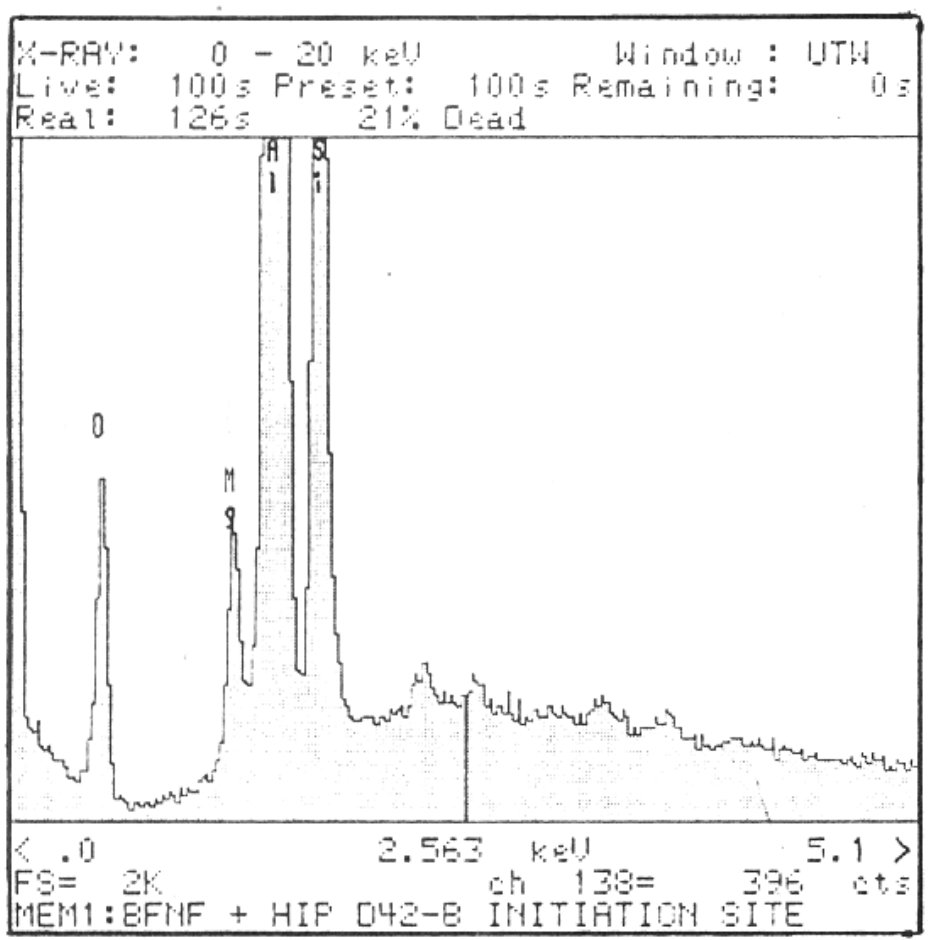

(b)

Figure 11 (a) Secondary electron micrograph showing a crack initiation oxide defect in an unfiltered non-hipped Al-7Si-Mg alloy casting; (b) Energy dispersive $\mathrm{x}$-ray microanalysis from a fatigue crack initiator (a). 


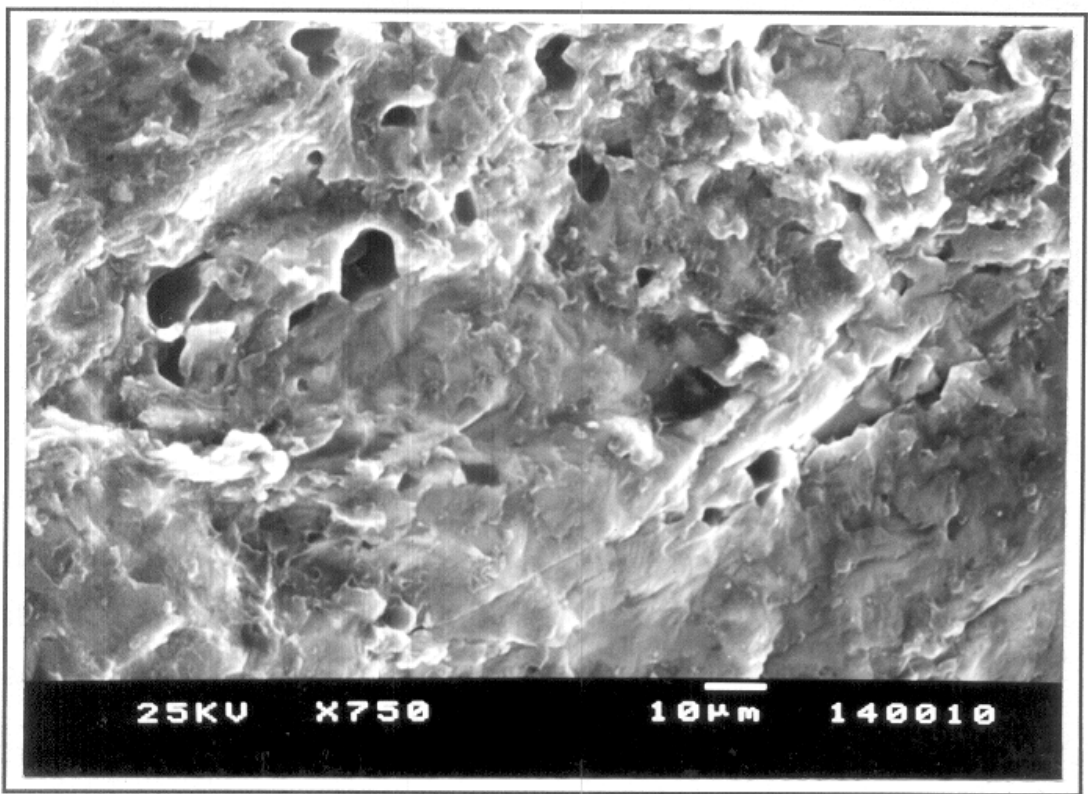

(a)

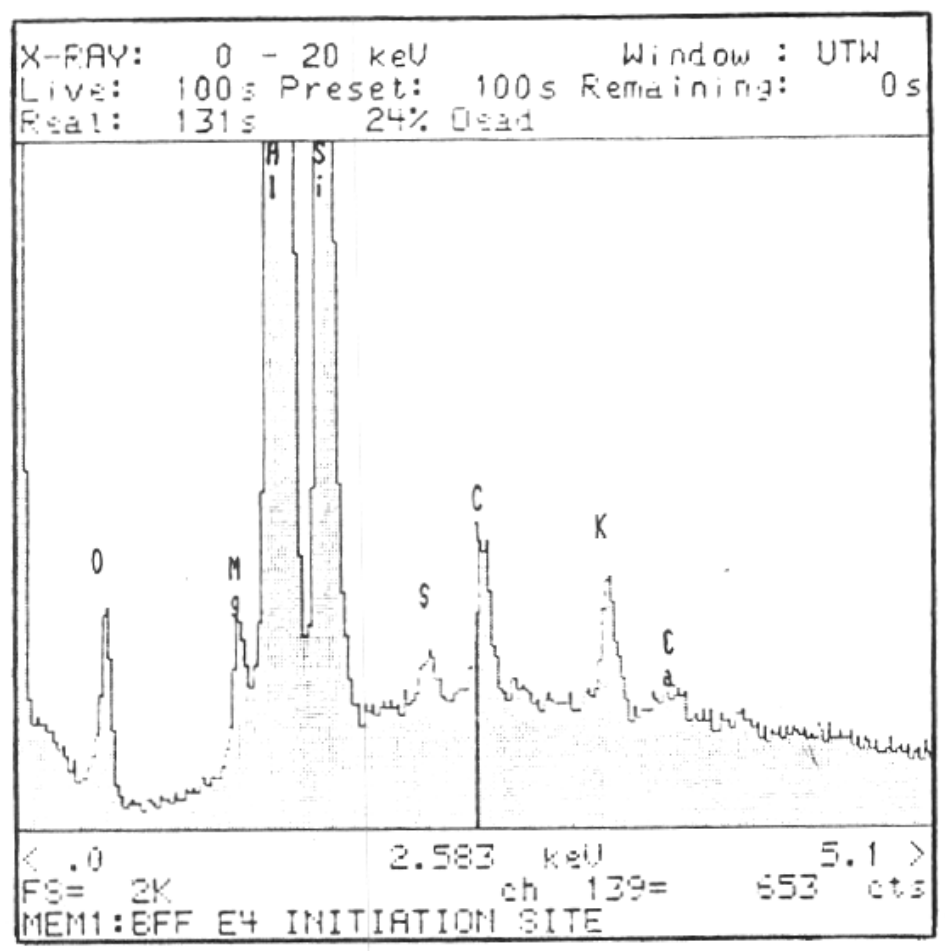

(b)

Figure 12 (a) Secondary electron micrograph showing a crack initiation oxide defect in an unfiltered hipped Al-7Si-Mg alloy casting; (b) Energy dispersive x-ray microanalysis from a fatigue crack initiator (a). 


\subsection{Quantification of the effectiveness of hipping on healing oxide film defects in cast aluminium alloys}

The lognormal statistical plot for the fatigue life data of the $150 \mathrm{MPa}$ unfiltered non-hipped castings is shown in Figure 13 and that of the $240 \mathrm{MPa}$ unfiltered non-hipped and unfiltered hipped castings is presented in Figure 14. The statistical parameters for $150 \mathrm{MPa}$ castings are summarized in Table 1 and are compared to those of Al-10Mg alloy castings [9, 11], and those for $240 \mathrm{MPa}$ castings are summarized in Table 2. The less damaging effect of oxide film defects in unfiltered hipped castings is reflected by both the higher average fatigue life and fatigue life below which 0.1 percent $\left(-3 S_{\text {In }}\right)$ of castings failed compared to the oxide film defects in the unfiltered non-hipped castings. This clearly indicates that, following hipping treatment there was a considerable improvement in fatigue lives of the castings. In other words, the oxide defects in the unfiltered hipped Al-7Si-Mg alloy castings were effectively de-activated as fatigue crack initiators by hipping process [15].

The average fatigue life of unfiltered hipped Al-7Si-Mg alloy castings is similar to that of non-hipped Al-10Mg alloy castings (Table 1), and their fatigue life distributions are similar (Figure 9). The extreme similarity in fatigue behaviour of the unfiltered non-hipped Al-7Si$\mathrm{Mg}$ and non-hipped $\mathrm{Al}-10 \mathrm{Mg}$ alloys is somewhat surprising. The Al-7Si-Mg alloy contains large amounts of brittle second phase, whereas the Al-10Mg material is a solid solution alloy of uniformly high ductility. The similarity of fatigue life behaviour therefore points to something fundamentally controlling the fatigue behaviour of both alloys, which may therefore be so general as to apply to all cast aluminium alloys. This underlines to importance of the presence of different kinds of oxides in controlling the fatigue properties of these alloys [20].

The standard deviation, which is a quantitative measure of the scatter in results about mean, is lower for unfiltered hipped Al-7Si-Mg alloy castings than for unfiltered non-hipped Al-7Si$\mathrm{Mg}$ alloy castings (Table 2), indicating that hipping process significantly reduced scatter of fatigue lives of the castings. However, the scatter of fatigue life data has been reported to be greater in hipped $\mathrm{Al}-10 \mathrm{Mg}$ alloy castings compared to that in non-hipped Al-10Mg [9, 11] (Table 1). High levels of oxide inclusions have been reported to be responsible for the large scatter in the fatigue properties of the castings. Since the magnesium film whose structure does not transform during hipping would, therefore, be resistant to forming bonds, hipping process may have produced ineffective bonding across the oxide-oxide interface in Al$10 \mathrm{Mg}$ alloy castings. This indicates clearly that oxide film structure in Al-7Si-Mg alloy differs in transformation response to effect bonding during hipping process compared to oxide film structure in $\mathrm{Al}-10 \mathrm{Mg}$. 


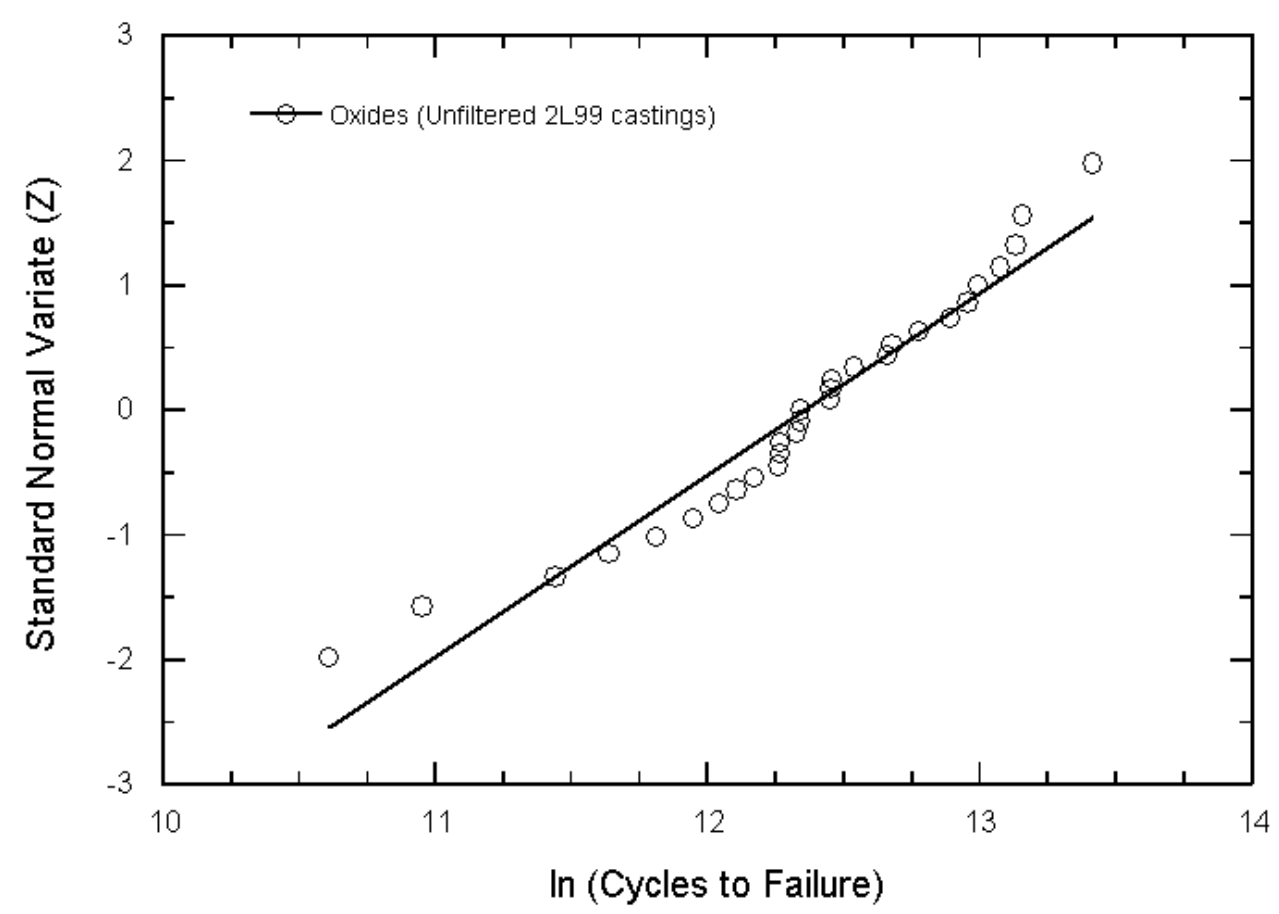

Figure 13 Standard lognormal plot for fatigue lives of $150 \mathrm{MPa}$ non-hipped Al-7Si-Mg alloy castings

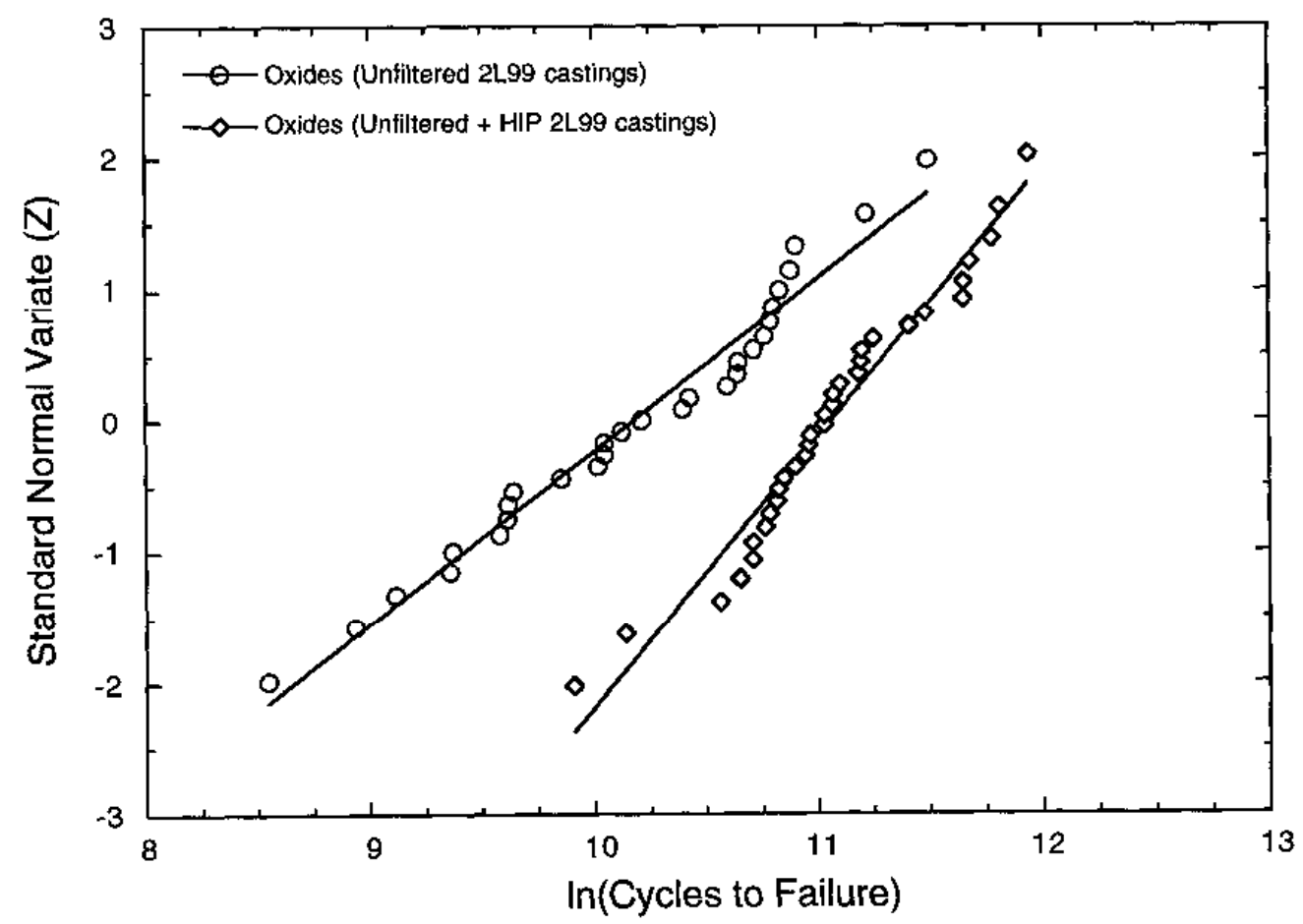

Figure 14 Standard lognormal plot for fatigue lives of $240 \mathrm{MPa}$ non-hipped and hipped Al-7Si-Mg alloy castings. 
Table 1 Comparison of predicted lognormal statistical parameters for fatigue life data of 150 MPa non-hipped and hipped Al-7Si-Mg alloy castings and those of non-hipped and hipped Al-10Mg alloy castings [9, 11].

Predicted Log-normal statistical parameters

\begin{tabular}{|c|c|c|c|c|c|}
\hline \multirow[b]{2}{*}{ Casting detail } & \multirow[b]{2}{*}{$\begin{array}{c}\text { Sample size } \\
n\end{array}$} & \multirow{2}{*}{\multicolumn{3}{|c|}{$\begin{array}{c}\ln (\text { fatigue life at } 0.1 \\
\text { percent of } \\
\text { specimens failed) } \\
(\ln N)_{\text {ave }}-3 S_{\ln } \\
\end{array}$}} & \multirow[b]{2}{*}{$\begin{array}{l}\text { Range } \\
\left(10^{5} \text { cycles }\right)\end{array}$} \\
\hline & & & & & \\
\hline $\begin{array}{l}\text { Unfiltered non-hipped } \\
\text { Al-7Si-Mg alloy castings }\end{array}$ & 29 & 12.3 & 0.67 & 10.3 & 0.4 to 6.71 \\
\hline $\begin{array}{l}\text { Unfiltered hipped Al- } \\
\text { 7Si-Mg alloy castings }\end{array}$ & 3 & $>16.6$ & * & * & All >170 \\
\hline $\begin{array}{l}\text { Non-hipped } \mathrm{Al}-10 \mathrm{Mg} \\
\text { alloy castings }[9,11]\end{array}$ & 18 & 12.3 & 0.42 & 11.04 & 1.04 to 4.70 \\
\hline $\begin{array}{l}\text { Hipped Al-10 Mg alloy } \\
\text { castings }[9,11]\end{array}$ & 19 & 13.6 & 1.18 & 10.06 & 1.60 to 85 \\
\hline
\end{tabular}

${ }^{*}$ All unfiltered hipped specimens were run-outs.

Table 2 Predicted lognormal statistical parameters for fatigue life data of $240 \mathrm{MPa}$ non-hipped and hipped of Al-7Si-Mg alloy castings.

\begin{tabular}{|c|c|c|c|c|c|}
\hline \multirow[b]{2}{*}{ Casting detail } & \multirow[b]{2}{*}{$\begin{array}{l}\text { Sample } \\
\text { size } \\
n\end{array}$} & \multicolumn{3}{|c|}{ Predicted Log-normal statistical parameters } & \multirow[b]{2}{*}{$\begin{array}{c}\text { Range } \\
\left(10^{4} \text { cycles }\right)\end{array}$} \\
\hline & & $(\ln N)_{\text {ave }}$ & $\begin{array}{l}\text { Standard } \\
\text { deviation } S_{\ln }\end{array}$ & $\begin{array}{l}\ln (\text { fatigue life at } \\
0.1 \text { percent of } \\
\text { specimens } \\
\text { failed }) \\
(\ln N)_{\text {ave }}-3 S_{\ln } \\
\end{array}$ & \\
\hline $\begin{array}{l}\text { Unfiltered non-hipped } \\
\text { Al-7Si-Mg alloy } \\
\text { castings }\end{array}$ & 29 & 10.2 & 0.76 & 7.9 & 0.5 to 9.8 \\
\hline $\begin{array}{l}\text { Unfiltered hipped Al- } \\
\text { 7Si-Mg alloy castings }\end{array}$ & 32 & 11.1 & 0.49 & 9.6 & 2 to 440 \\
\hline
\end{tabular}




\section{CONCLUSIONS}

Oxide film defects in the turbulent unfiltered non-hipped castings constitute cracks showing no bond developed across the oxide-oxide interface. Widths between the two dry surfaces of folded oxide film have been found to vary between 1 and $10 \mu \mathrm{m}$. Widths of cracks associated with pores are substantially greater than $10 \mu \mathrm{m}$. Unlike the crack-like nature of oxides in the unfiltered non-hipped, crack widths of oxide film defects in unfiltered hipped castings are less than $1 \mu \mathrm{m}$. This is evidence that closure, diffusion bonding and reduction in size of oxide film defects occurred during hipping treatment.

The average fatigue life and fatigue life at 0.1 percent failure rate of Al-7Si-Mg alloy castings improve significantly following hipping treatment that also reduces considerably the scatter of the fatigue life data of the castings. This indicates that solid state hot isostatic pressing is a robust process to de-activate oxide film defects as fatigue crack initiators in Al-7Si$\mathrm{Mg}$ alloy castings in which transformation of oxide film structure does promote the diffusion bonding across oxide film interfaces. This, however, contrasts with the behaviour of oxide inclusions in $\mathrm{Al}-10 \mathrm{Mg}$ alloy castings in which magnesium oxide film, whose structure is stable and does not transform during hipping, is possibly resistant to form effective bonding across oxide film interfaces.

\section{ACKNOWLEDGEMENTS}

The author is grateful to the University of Birmingham through the School of Metallurgy and Materials and the University of Dar es Salaam for the support of this research work.

\section{REFERENCES}

1. A. Demaid and J.H.W. de Wit (1995), Case Studies in Manufacturing with Advanced Materials, pub. Elservier, pp. 177 - 195.

2. H.V. Atkinson and S. Davies (2000), Fundamental Aspects of Hot Isotatic Pressing: An Overview, Metallurgical and Materials Transactions A, pp. 2981.
3. E.L. Rooy (1983), Hot Isostatic Process, AFS Transactions, 91, pp. $607-612$.

4. H.D. Hanes (1980), Hot Isostatic Pressing of Premium Quality Castings, $12^{\text {th }}$ National SAMPE Technical Conference, (October 7-9, 1980), pp. $1074-1084$.

5. G.V. Scarich (1983), Hot Isostatic Pressing of Aluminium Castings, 28th National SAMPE Symposium, (April 12-14, 1983), pp. $1329-1339$.

6. Metals Handbook, Volume 15, Ninth Edition, American Society for Metals, (1988), pages 538 - 544 and $757-762$.

7. C.C. Chama (1992), Mechanical Properties of Hot Isostatically Pressed AluminiumSilicon Castings, Scripta Metallurgica et Materialia, 26, pp. 1153 - 1156.

8. G.R. Wakefield and R.M. Sharp (1991), Hot Isostatically Pressing of Al-10\% Mg Alloy Castings, Materials Forum, 15, pp. $268-273$.

9. G.R. Wakefield and R.M. Sharp (1992), Fatigue Properties of Hot Isostatically Pressed Al-10Mg Castings, Materials Science and Technology, 8, pp. 1125 1129.

10. M.W. Ozelton, S.J. Mocarski and P.G. Porter (1991), Durability and Damage Tolerance of Aluminium Castings, WL-TR91-4111.

11. G.R. Wakefield and R.M. Sharp (1992), Fatigue Properties of Hot Isostatically Pressed Al-10Mg Castings, Materials Science and Technology, 8, pp. 1125 1129.

12. C. Lipson and N.T. Sheth (1973), Statistical Design and Analysis of Engineering Experiments, Mc Graw - Hill, USA.

13. J. Schijve (1994), Fatigue Predictions and Scatter, J. of Fatigue Fracture Engineering Materials Structure, 17 (4), pp. 381 - 644. 
14. G.R. Wakefield and R.M. Sharp (1996), Effect of Casting Technique on Fatigue Properties of Hot Isostatically Pressed Al$10 \mathrm{Mg}$ Castings, Materials Science and Technology, 12, pp. 518 - 522.

15. C. Nyahumwa, N.R. Green, and J. Campbell (2000), Influence of Casting Technique and Hot Isostatic Pressing on the Fatigue of an Al-7Si-Mg Alloy, Metallurgical and Materials Transactions A, 31A, pp. 1 - 10 .

16. A. Sunwoo and R. Lum (1995), Superplastic Deformation Enhanced Diffusion Bonding of Aluminium Alloy 7475, Scripta Metallurgica et Materialia, 33 (4), pp. $639-644$.

17. A. Sunwoo (1994), Diffusion Bonding of Aluminium Alloy 8090, Scripta
Metallurgica et Materialia, 31 (4), pp. 407 -412 .

18. R.S. Bushby, K.P. Hicks and V.D. Scott (1996), Joining Molybdenum to Aluminium by Diffusion Bonding, J. of Materials Science, 31 (1996), pp. 4545 - 4552.

19. W. Hu, D. Ponge and G. Gottstein (1995), Origin of Grain Boundary Motion during Diffusion Bonding by Hot Pressing, J. of Materials Science and Engineering, A190, pp. $223-229$.

20. C. Nyahumwa, N.R. Green, and J. Campbell (1998), Effect of Mould-Filling Turbulence on Fatigue Properties of Cast Aluminium Alloys, AFS Transactions, 106, pp. $215-223$. 